\title{
ANALISA STABILITAS LERENG PADA CAMPURAN PASIR DAN TANAH LEMPUNG DENGAN MENGGUNAKAN PERMODELAN DI LABORATORIUM
}

\author{
Anissa Maria Hidayati ${ }^{1}$
}

\begin{abstract}
ABSTRAK
Tanah longsor merupakan potensi bencana geologis berupa pergerakan tanah yang terjadi karena perubahan keseimbangan daya dukung tanah dan akan berhenti setelah mencapai keseimbangan baru. Selain itu tanah longsor merupakan salah satu fenomena alam yang tidak terkontrol yang menarik perhatian manusia karena berpotensi membahayakan keselamatan manusia. Analisa stabilitas lereng dilakukan untuk mengevaluasi kondisi kestabilan lereng dan ditujukan untuk mendapatkan angka faktor keamanan dari suatu bentuk lereng tertentu. Dengan diketahuinya faktor keamanan memudahkan pekerjaan pembentukan atau perkuatan lereng untuk memastikan apakah lereng yang telah dibentuk mempunyai resiko longsor atau cukup stabil.Pengujian dilakukan di laboratorium dengan membuat pemodelan lereng dengan ukuran $13 \times 0,2 \times 0,6$ meter. Pemodelan lereng diletakkan di atas meja getar yang di dalamnya telah diberi campuran tanah lempung dan pasir dengan persentase $90 \%$ pasir dan $10 \%$ tanah lempung.Selanjutnya sebagai getaran gempa, shaking-table digetarkan, dan pencatatan terhadap getaran gempa ini dilakukan dengan menggunakan accelogram. Bentuk output dari accelogram ini dicatat dengan accelegraf dengan menggunakan program G-Trace.
\end{abstract}

Kata Kunci : tanah longsor, stabilitas lereng, tanah lempung dan pasir, G-Trace

\section{TINJAUAN PUSTAKA}

\subsection{Tanah}

Tanah dalam pengertian teknik secara umum didefenisikan sebagai material yang terdiri dari agregat (butiran) mineral-mineral padat yang tidak tersedimentasi (terikat secara kimia) satu sama lainnya dan dari bahan-bahan organik yang telah melapuk (yang berpartikel padat) disertai dengan zat cair dan gas-gas yang mengisi ruang-ruang kosong diantara partikel-partikel padat tersebut.

Tanah lempung di dalam kasus ini sebagai tanah dasar dari lereng. Tanah lempung mempunyai ukuran partikel yang lebih kecil dari 0,002 $\mathrm{mm}$. Menurut Bowles (1884) tanah lempung adalah deposit yang mempunyai partikel yang berukuran lebih kecil atau sama dengan 0,002 mm. Mineral lempung mempunyai daya tarik menarik individual yang mampu menyerap 100 kali volume partikelnya. Ada atau tidak adanya air (selama pengeringan) dapat menghasilkan perobahan volume dan kekuatan yang sangat besar.

\subsection{Gerakan Tanah}

Pengertian longsoran (landslide) dengan gerakan tanah (mass movement) mempunyai kesamaan. Untuk memberikan definisi longsoran perlu penjelasan keduanya. Gerakan tanah ialah perpindahan massa tanah/batu pada arah tegak, mendatar atau miring dari kedudukan semula. Gerakan tanah mencakup gerak rayapan dan aliranmaupun longsoran. Menurut definisi ini longsoran adalah bagian gerakan tanah. Jika menurut definisi ini perpindahan massa tanah/batu pada arah tegak adalah termasuk gerakan tanah, maka gerakan vertikal yang mengakibatkan bulging (lendutan)

${ }^{1}$ Jurusan Teknik Sipil- Fakultas Teknik Universitas Udayana 
akibat keruntuhan fondasi dapat dimasukkan pula dalam jenis gerakan tanah. Dengan demikian pengertiannya menjadi sangat luas.

Klasifikasi gerakan tanah :

1. Runtuhan

2. Jungkiran

3. Longsoran

4. Penyebaran lateral

5. Aliran

6. Pergerakan majemuk

\subsection{Analisa Stabilitas Lereng}

Analisa stabilitas lereng dilakukan untuk mengevaluasi kondisi kestabilan lereng dan untuk kerja dari lereng galian, lereng timbunan, maupun lereng alami. Secara umum tujuan dari analisa kestabilan lereng adalah sebagai berikut :

a. Untuk menentukan kondisi kestabilan suatu lereng

b. Memperkirakan bentuk keruntuhan atau longsoran yang mungkin terjadi

c. Menentukan tingkat kerawanan lereng terhadap longsoran

d. Menentukan metode perkuatan atau perbaikan lereng yang sesuai

Selain itu, analisa stabilitas lereng ditujukan untuk mendapatkan angka faktor keamanan dari suatu bentuk lereng tertentu. Dalam analisis kestabilan lereng umumnya digunakan persamaan Mohr Coulomb, untuk menyatakan kekuatan geser material.

Persamaan Mohr Coulomb dalam bentuk tegangan efektif adalah sebagai berikut :

$\tau=c+\sigma \tan \varnothing$

dimana :

$\tau=$ tegangan geser

$\mathrm{c}=$ kohesi

$\sigma=$ tegangan normal

$\emptyset=$ sudut geser tanah

Faktor aman didefinisikan sebagai nilai banding antara gaya yang menahan dan gaya yang menggerakkan, atau :

$$
\mathrm{F}=\frac{\tau}{\tau_{\mathrm{u}}}
$$

dimana :

$\mathrm{F}=$ faktor aman

$\tau=$ tahanan geser maksimum yang dapat dikerahkan oleh tanah

$\tau_{\mathrm{d}}=$ tegangan geser yang terjadi akibat gaya berat tanah yang akan longsor

\subsection{Metode Irisan}

Analisa stabilitas lereng dengan menggunakan metode irisan, dapat dijelaskan dengan menggunakan gambar (Gambar 1.) dengan AC merupakan lengkungan lingkaran sebagai permukaan bidang longsor percobaan.

Untuk pengamatan keseimbangan :

$$
\mathrm{N}_{\mathrm{r}}=\mathrm{W}_{\mathrm{n}} \cos \alpha_{3}
$$

\section{2 | J URNAL REKAYASA SIPIL}


Gaya geser perlawanan dapat dinyatakan sebagai berikut :

$$
\mathrm{T}_{\mathrm{r}}=\tau_{\mathrm{d}}\left(\Delta \mathrm{L}_{\mathrm{n}}\right)=\frac{\tau_{\mathrm{f}}\left(\Delta \mathrm{L}_{\mathrm{n}}\right)}{\mathrm{F}_{\mathrm{s}}}=\frac{1}{\mathrm{~F}_{s}}[\mathrm{c}+\sigma \tan \emptyset] \Delta \mathrm{L}_{\mathrm{n}}
$$

Untuk keseimbangan blok percobaan $\mathrm{ABC}$, momen gaya dorong terhadap titik adalah sama dengan momen gaya perlawanan terhadap titik $\mathrm{O}$, atau

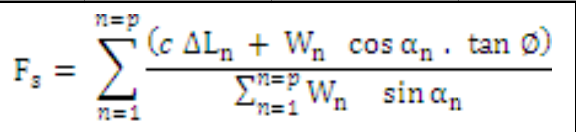

Dengan :

Fs = faktor aman

$\Delta \mathrm{Ln}=$ panjang bagian lingkaran pada irisan ke-n

$\mathrm{Wn}=$ berat irisan tanah ke-n

$\mathrm{c}=$ kohesi tanah

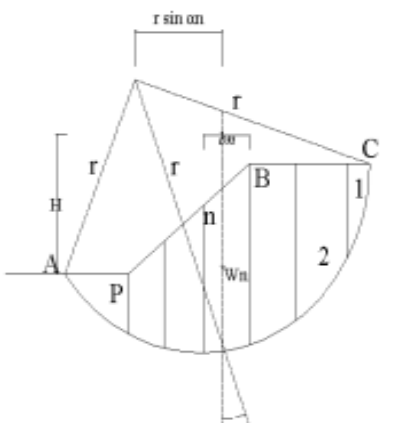

a. Permukaan Bidang yang Dicoba

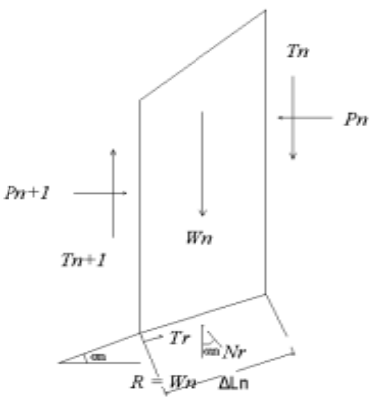

b. Gaya yang Bekerja pada Irisan

Gambar 1.Analisa Stabilitas dengan Metode Irisan Biasa

\section{PELAKSANAAN PERCOBAAN}

\subsection{Pemodelan Alat}

Pada tahapan ini dilakukan percobaan dengan menggunakan sebuah pemodelan lereng yang terbuat dari kaca yang diletakkan pada alat shaking table yang telah dipersiapkan. Pemodelan lereng tersebut terbuat dari kaca yang berukuran $13 \times 0,2 \times 0,6$ meter.

\subsection{Prosedur Percobaan}

a. Persiapkan alat pemodelan lereng di atas meja getar sebagai tempat campuran pasir dan tanah lempung(Gambar 2.).

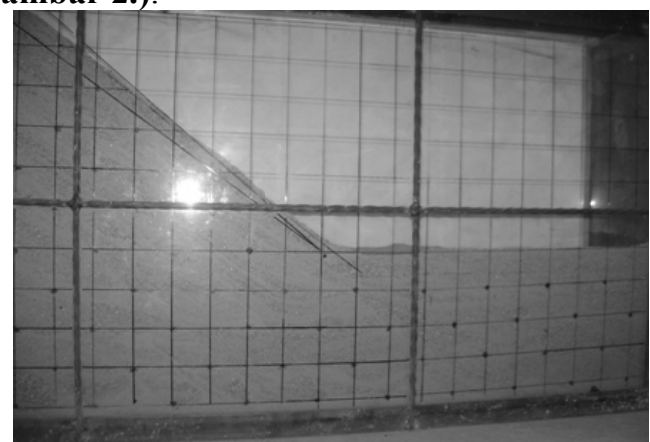

Gambar 2. Pemodelan Lereng Campuran Pasir dan Tanah Lempung (90\%:10\%) 
b. Masukkan campuran pasir dan tanah lempung ke dalam bejana kaca dengan persentase campuran $90 \%$ pasir, $10 \%$ tanah lempung tanpa dipadatkan.

c. Kemudian campuran tersebut diatur sedemikian rupa sehingga membentuk lereng dengan kemiringan menggunakan nilai sudut gesernya.

d. Beri tanda pada setiap jarak $10 \mathrm{~cm}$ pada campuran tersebut dengan menggunakan bambu untuk memudahkan melihat seberapa besar perubahan yang terjadi setelah bejana kaca digetarkan.

e. Setelah sempel dipersiapkan, kemudian pasang alat accelerogram pada meja getar.Accelerogram ini berfungsi untuk me-record getaran yang terjadi(Gambar 3.).

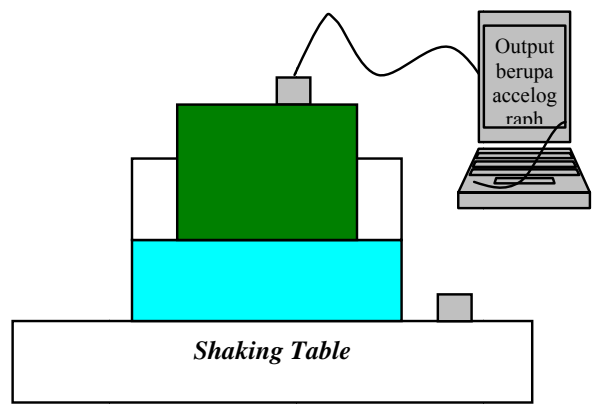

\section{Gambar 3. Susunan Benda Uji dan Accelogram di Atas Meja Getar}

f. Getarkan Shaking Table. Pencatatan getaran dilakukan oleh alat yang disebut accelogram(Gambar 4). Hasil pencatatan accelogram dapat dilihat pada komputer berupa grafik atau biasa disebut accelograph. Hasil output pada komputer dapat dilihat melalui program G-Trace.

g. Amati apa yang terjadi pada bejana kaca selama digetarkan.

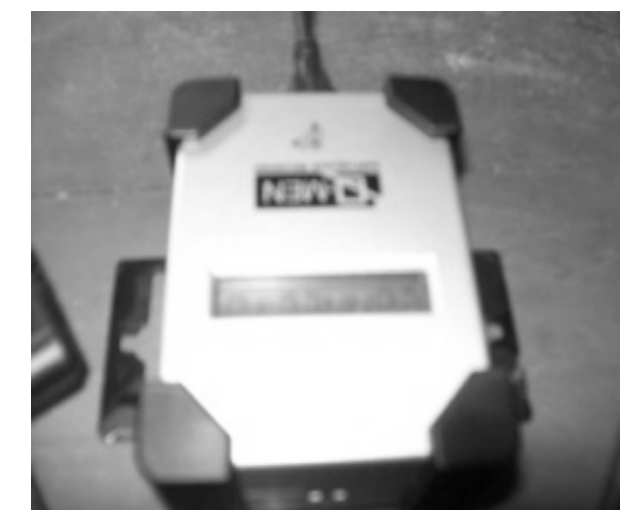

Gambar 4. Alat Pencatat Getaran G-Men

\section{HASIL PENELITIAN}

\subsection{Parameter-Parameter Tanah}

1. Berat volume tanah $(\gamma d)$ $\gamma d=1.3576 \mathrm{~g} / \mathrm{cm}^{3}$

2. Kohesi (c) $\mathrm{c}=0.14$

3. Sudut geser $(\Phi)$ $\Phi=39.35^{\circ}$

\section{4 | J URNAL REKAYASA SIPIL}




\subsection{Hasil Percobaan}

\subsubsection{Percepatan Meja Getar Pada Campuran Sampel 90\% Pasir dan 10\% Tanah Lempung}

Pada saat meja getar digetarkan, data dari getaran di ukur dengan G-trace yang output-nya dalam bentuk grafik(Gambar 5-7.).Dari grafik diketahui :

- Percobaan 1

amax rata-rata

Perioda (T)

Frekuensi (f)

$$
=4.802 \mathrm{~m} / \mathrm{s}^{2}
$$$$
=0.154 \mathrm{dt}
$$$$
=6.49 \mathrm{~Hz}
$$

Frekuensi natural sudut $(\omega)=40.78 \mathrm{~Hz}$

- Percobaan 2

amax rata-rata

Perioda (T)

$$
=10.682 \mathrm{~m} / \mathrm{s} 2
$$

Frekuensi (f)

$=1.692 \mathrm{dt}$

Frekuensi natural sudut $(\omega)=3.713 \mathrm{~Hz}$

- Percobaan 3

$\begin{array}{ll}\text { amax rata-rata } & =7.252 \mathrm{~m} / \mathrm{s} 2 \\ \text { Perioda }(\mathrm{T}) & =1.496 \mathrm{dt} \\ \text { Frekuensi (f) } & =0.669 \mathrm{~Hz} \\ \text { Frekuensi natural sudut }(\omega) & =4.201 \mathrm{~Hz}\end{array}$

Grafik Percepatan campuran sampel dengan Getaran Pada Meja Getar

Percobaan 1

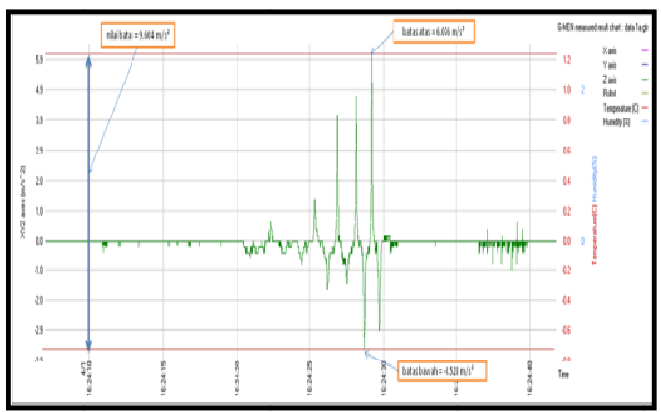

Gambar 5.Grafik Percepatan Campuran Sampel Dengan Getaran Pada Meja Getar Percobaan 2

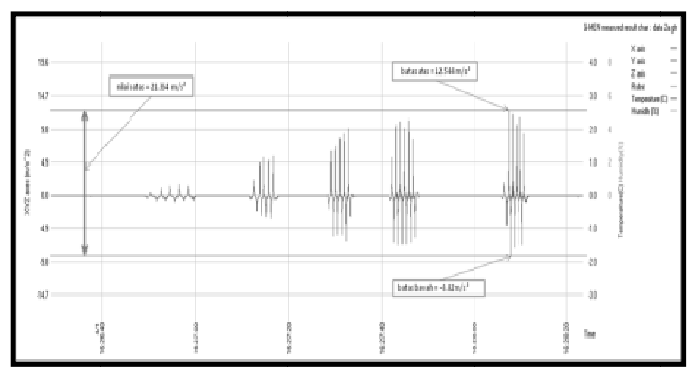

Gambar 6. Grafik Percepatan Campuran Sampel Dengan Getaran Pada Meja Getar 
Percobaan 3

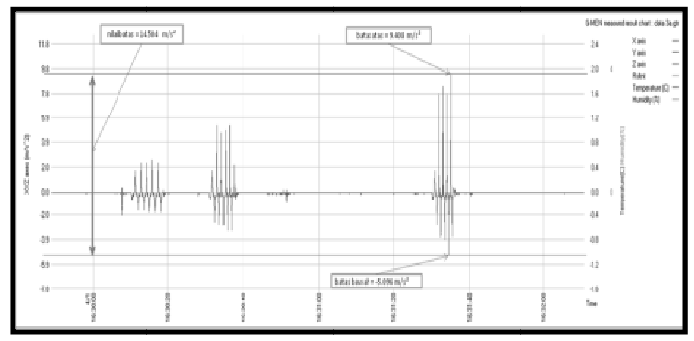

Gambar 7. Grafik Percepatan Campuran Sampel Dengan Getaran Pada Meja Getar

\subsubsection{Pemodelan Lereng Setelah Digetarkan}

Setelah meja getar digetarkan yang secara langsung memberikan getaran pada pemodelan lereng. Lereng mengalami keruntuhan dan penurunan, penurunan ini terjadi karena pemadatan masa tanah akibat getaran yang diberikan(Gambar 8.). Keruntuhan dan penurunan yang terjadi (Gambar 911.) dapat dilihat dengan cara pengamatan.

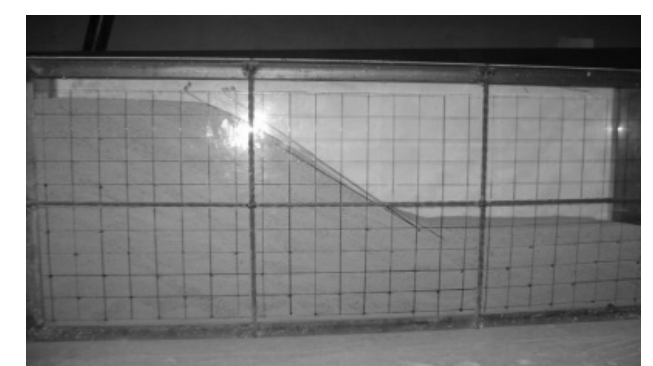

\section{Gambar 8.Bentuk Lereng Setelah Digetarkan}

Pergerakan butiran dan garis keruntuhan lereng percobaan 1

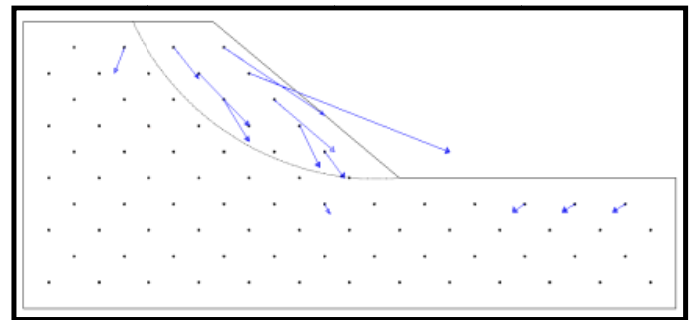

Gambar 9.Pergerakan Butiran dan Garis Keruntuhan Pada Percobaan Pertama

Pergerakan butiran dan garis keruntuhan lereng percobaan 2

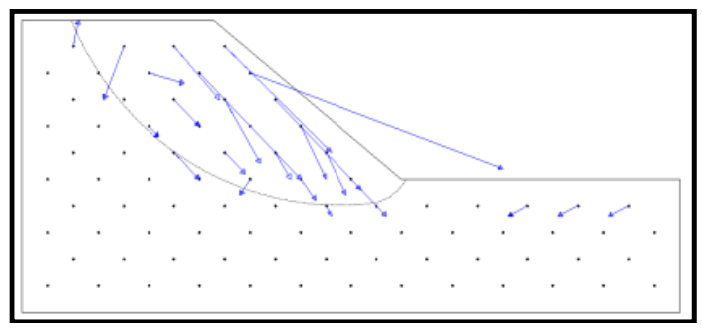

Gambar 10.Pergerakan Butiran dan Garis Keruntuhan Pada Percobaan Kedua

\section{6 | J URNAL REKAYASA SIPIL}


Pergerakan butiran dan garis keruntuhan lereng percobaan 3

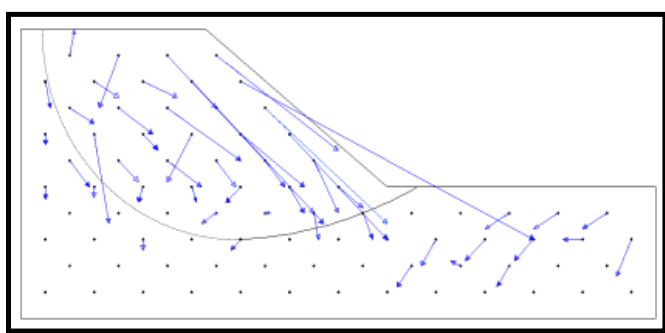

Gambar 11. Pergerakan Butiran dan Garis Keruntuhan Pada Percobaan Ketiga

\subsubsection{Perubahan Bentuk Pemodelan Lereng Setelah Digetarkan}

Pada saat tanah pengalami getaran dapat menyebabkan perubahan bentuk(Gambar 12.), karena butiran mengalami pergerakan.

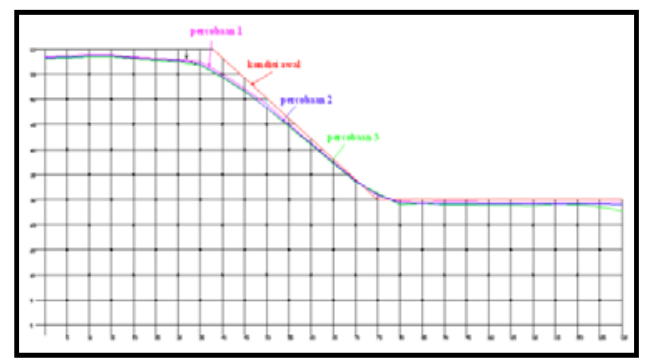

Gambar 12.Perubahan Bentuk Lereng

\subsection{Pembahasan}

Gaya-gaya yang bekerja pada lereng secara umum dapat di kelompokkan menjadi dua yaitu gayagaya yang cenderung untuk menyebabkan material pada lereng bergerak ke bawah dan gaya-gaya yang menahan material pada lereng sehinggga tidak terjadi peretakan atau longsoran. Berdasarkan hal tersebut, Terzaghi membagi penyebab-penyebab terjadinya longsor menjadi dua kelumpok yaitu penyebab ekternal yang menyababkan naiknya gaya geser yang bekerja sepanjang bidang runtuh (Das, 1995). Dalam hal ini salah satu penyababnya adalah gaya vibrasi yang ditimbulkan oleh gempa bumi, dalam pengujian ini dapat dilihat gempa yang terjadi sangat mempengaruhi kestabilan lereng. Penyebab yang kedua yaitu penyebab internal yang menyebabkan turunnya kuat geser material.

Gempa dapat mengakibatkan ketidakstabilan lereng dari kondaisi awal stabil. Getaran yang diterima tanah dapat merubah kondisi struktur tanah. Pada campuran tanah dalam keadaan kering beban gempa yang diterima mengakibatkan pergerakan butiran ,sehingga butiran menjadi lebih rapat.

Dari hasil pengujian dapat dilihat bahwa percepatan maksimum rata-rata terbesar terdapat dapat pada percobaan 2 yaitu $10.682 \mathrm{~m} / \mathrm{s}^{2}$. Pada masing-masing percobaan, besarnya getaran yang diberikan tidak sama. Dimulai dari getaran yang kecil sampai yang besar. Pada Gambar 13-15. dapat dilihat bahwa getaran yang di berikan pada sampel tidak mengakibatkan seluruh butiran mengalamideformasi.

Keruntuhan yang signifikan dapat terlihat dari deformasi butiran pada bagian atas sampel perpindahan yang terjadi sangat besar. Pada bagian dasar lereng setelah beberapa getaran keadaan 
lereng memadat sehingga antara butiran saling mengunci, jika dilihat dari data perpindahan butiran dan terlihat juga pada Gambar 13 s.d 15.hampir tidak terjadi pergerakan.Kemudian dari pergerakan butiran dapat di hitung angka keamanan lereng Fs(Tabel 1 s.d 3.). Penghitungan menggunakan Metode Irisan (Method Of Slices), dapat dilihat dari gambar pergerakan butiran.

\subsection{PerhitunganAngka Keamanan Dengan Metode Irisan}

Dengan formula sebagai berikut :

$\mathrm{Fs}=\Sigma\left(\mathrm{c} \times \Delta \mathrm{l}_{\mathrm{n}}+\mathrm{W}_{\mathrm{n}} \times \cos \alpha_{\mathrm{n}} \times \tan \emptyset\right) / \Sigma \mathrm{W}_{\mathrm{n}} \sin \alpha_{\mathrm{n}}$

- Angka keamanan pada percobaan pertama

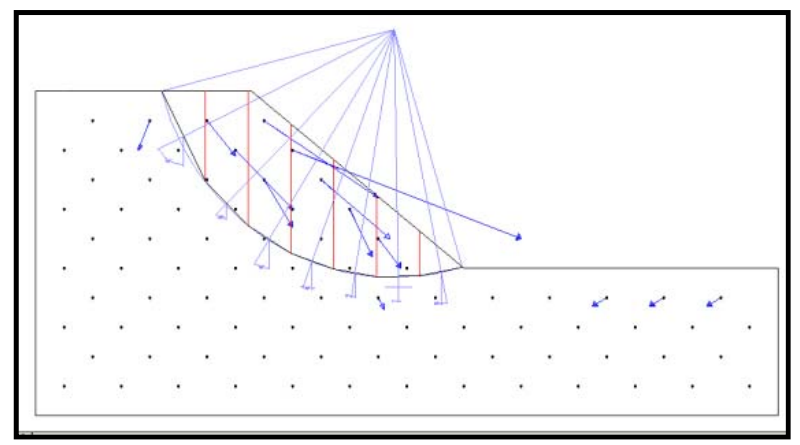

Gambar 13.Lengkung Keruntuhan Untuk Getaran Pertama

Tabe 1.Perhitungan FS Untuk Percobaan Pertama

\begin{tabular}{|c|c|c|c|c|c|c|c|}
\hline irisan no & Wn (g/cm) & $\boldsymbol{\alpha n}\left(^{\circ}\right)$ & $\sin \boldsymbol{\alpha n}$ & $\cos \boldsymbol{\alpha n}$ & $\Delta \mathbf{L n}(\mathbf{c m})$ & $\begin{array}{c}\text { Wn sin } \boldsymbol{\alpha n} \\
\mathbf{g} / \mathbf{c m})\end{array}$ & $\begin{array}{c}\text { Wn cos } \boldsymbol{\alpha n} \\
\mathbf{g} / \mathbf{c m})\end{array}$ \\
\hline 1 & 78.0507 & 64 & 0.8988 & 0.4384 & 17.038 & 70.1520 & 34.2174 \\
\hline 2 & 196.9526 & 45 & 0.7071 & 0.7071 & 10.6125 & 139.2652 & 139.2652 \\
\hline 3 & 230.3451 & 32 & 0.5299 & 0.848 & 8.8299 & 122.0599 & 195.3326 \\
\hline 4 & 206.2584 & 20 & 0.342 & 0.9397 & 8.0084 & 70.5404 & 193.8210 \\
\hline 5 & 164.8006 & 9 & 0.1564 & 0.9877 & 7.6236 & 25.7748 & 162.7735 \\
\hline 6 & 108.6918 & -1 & -0.0175 & 0.9998 & 7.5208 & -1.9021 & 108.6700 \\
\hline 7 & 38.5781 & -11 & -0.1908 & 0.9816 & 7.6665 & -7.3607 & 37.8683 \\
\hline
\end{tabular}

$\mathrm{Fs}=11.13$

- Angka keamanan pada percobaan kedua

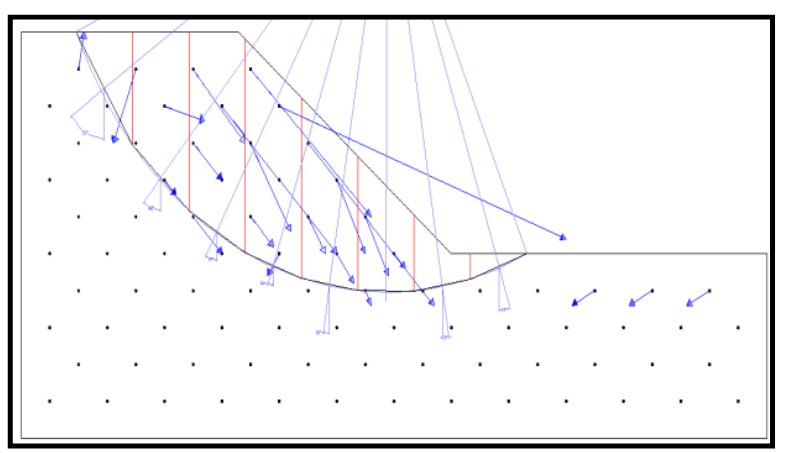

Gambar 14.Lengkung Keruntuhan Untuk Getaran Kedua

\section{8 | J URNAL REKAYASA SIPIL}


Tabe 2. Perhitungan FS Untuk Percobaan Kedua

\begin{tabular}{|c|c|c|c|c|c|c|c|}
\hline irisan no & Wn (g/cm) & $\boldsymbol{\alpha n}\left({ }^{\circ}\right)$ & $\sin \boldsymbol{\alpha n}$ & $\cos \boldsymbol{\alpha n}$ & $\boldsymbol{\Delta} \mathbf{L n}(\mathbf{c m})$ & $\begin{array}{c}\text { Wn sin } \boldsymbol{\alpha n} \\
\mathbf{g} / \mathbf{c m})\end{array}$ & $\begin{array}{c}\text { Wn cos } \boldsymbol{\alpha n} \\
\mathbf{g} / \mathbf{c m})\end{array}$ \\
\hline 1 & 101.8108 & 57 & 0.8387 & 0.5446 & 18.155 & 85.3887 & 55.4461 \\
\hline 2 & 268.2358 & 42 & 0.6691 & 0.7431 & 13.2288 & 179.4766 & 199.3260 \\
\hline 3 & 359.0089 & 30 & 0.5 & 0.866 & 11.362 & 179.5045 & 310.9017 \\
\hline 4 & 355.0417 & 20 & 0.342 & 0.9397 & 10.4288 & 121.4243 & 333.6327 \\
\hline 5 & 283.9836 & 10 & 0.1633 & 0.9848 & 9.96741 & 46.3745 & 279.6670 \\
\hline 6 & 189.7687 & 0 & 0 & 1 & 9.8241 & 0.0000 & 189.7687 \\
\hline 7 & 79.5543 & -9 & -0.1564 & 0.9877 & 9.9574 & -12.4423 & 78.5758 \\
\hline 8 & 22.8443 & -19 & -0.3256 & 0.9455 & 10.4042 & -7.4381 & 21.5993 \\
\hline
\end{tabular}

$\mathrm{Fs}=15.10$

- Angka keamanan pada percobaan ketiga

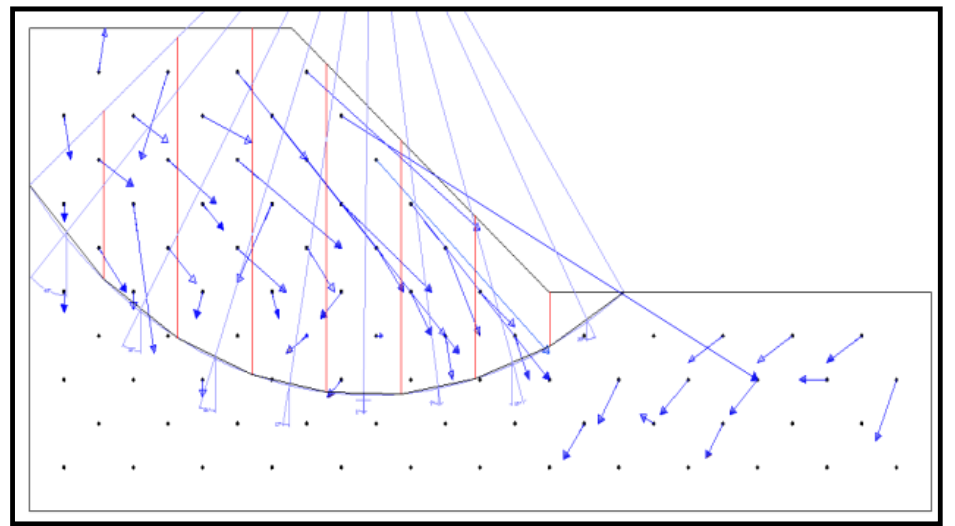

Gambar 15.Lengkung Keruntuhan Untuk Getaran Ketiga

Tabe 3.Perhitungan FS Untuk Percobaan Ketiga

\begin{tabular}{|c|c|c|c|c|c|c|c|}
\hline irisan no & Wn (g/cm) & $\boldsymbol{\alpha n}\left(^{\circ}\right)$ & $\sin \boldsymbol{\alpha n}$ & $\cos \boldsymbol{\alpha n}$ & $\Delta \mathbf{L n}(\mathbf{c m})$ & $\begin{array}{c}\text { Wn sin } \boldsymbol{\alpha n} \\
\mathbf{g} / \mathbf{c m})\end{array}$ & $\begin{array}{c}\text { Wn } \cos \boldsymbol{\alpha n} \\
\mathbf{g} / \mathbf{c m})\end{array}$ \\
\hline 1 & 138.9191 & 45 & 0.7071 & 0.7071 & 15.1176 & 98.2297 & 98.2297 \\
\hline 2 & 388.1457 & 32 & 0.5299 & 0.8480 & 12.6552 & 205.6784 & 329.1476 \\
\hline 3 & 542.2807 & 21 & 0.3584 & 0.9336 & 11.4363 & 194.3534 & 506.2733 \\
\hline 4 & 573.9688 & 11 & 0.1908 & 0.9816 & 10.9109 & 109.5133 & 563.4078 \\
\hline 5 & 481.7183 & 1 & 0.0170 & 0.9998 & 10.7195 & 8.1892 & 481.6220 \\
\hline 6 & 344.8614 & -9 & -0.1564 & 0.9877 & 10.8508 & -53.9363 & 340.6196 \\
\hline 7 & 179.5699 & -19 & -0.3256 & 0.9455 & 11.3468 & -58.4680 & 169.7833 \\
\hline 8 & 45.1938 & -30 & -0.5000 & 0.8660 & 12.3756 & -22.5969 & 39.1379 \\
\hline
\end{tabular}

$\mathrm{Fs}=17.67$ 


\section{KESIMPULAN}

Berdasarkan penelitian dan analisis yang dilaksanakan dengan sampel campuran tanah lempung $90 \%$ dan pasir $10 \%$ maka dapat diambil kesimpulan sebagai berikut :

1. Nilai angka kemanan (FS) tergantung dari sifat fisik/mekanik tanah, yaitu :

- Sudut geser $(\Phi)$

- Kohesi/daya ikat tanah (c)

- Berat isi $(\gamma)$

- Susunan tanah/batuan serta sudut lereng

2. Dari nilai angka keamanan yang didapatkan dapat dikatakan lereng cukup stabil.

3. Pada saat meja getar digetarkan, terjadi perpindahan butiran pada campuran sampel tanah, namun perpindahan yang terjadi tidak begitu besar, dikarenakan meja getar digetarkan secara manual, dengan percepatan yang bervariasi.

\section{DAFTAR KEPUSTAKAAN}

Bowles, J. E., (1984),"Foundation Analysis and Design", McGraw-Hill Book Company, Singapore.

Das, Braja M, (1995), (translated by Mochtar.N.E and Mochtar I.B.),"MekanikaTanah (Prinsipprinsip Rekayasa Geoteknis) Jilid I",Jakarta, Erlangga. 